\title{
Definição terminológica: princípios e regras
}

Terminological definition: principles and rules

Daniel de Sá RODRIGUES*

Instituto Federal da Paraíba (IFPB)

RESUMO: A definição de um termo de uma especialidade é elaborada conforme princípios e regras. Tendo isso em vista, este trabalho tem como objetivo demonstrar os princípios e regras de definição terminológica, de modo a levar aos iniciantes na área de Terminologia um conhecimento básico sobre definição e serem incentivados ao aprofundamento no assunto. Para tanto, inicialmente delimitamos o conceito de definição terminológica e, na sequência, expomos os oito princípios com suas regras de definição, demonstrados com exemplos de definição satisfatória e insatisfatória, conforme o caso. Esse tema é muito importante, especialmente para estudantes de cursos (ou de disciplinas) em que é necessário lidar com esse tipo de definição.

PALAVRAS-CHAVE: Definição Terminológica. Princípios de Definição. Regras de Definição.

ABSTRACT: Definition of a specialty term is prepared according to principles and rules. With this in mind, this work aims to demonstrate the principles and rules of terminological definition, in order to give beginners in the field of Terminology a basic knowledge about definition and be encouraged to deepen the subject. To this purpose, we first delimited the concept of terminological definition and, subsequently, we explained the eight principles with their definition rules, demonstrated with examples of satisfactory and unsatisfactory definition, according to the circumstances. This theme is very important, especially for students of courses (or disciplines) in which it is necessary to deal with this type of definition.

KEYWORDS: Terminological Definition. Definition Principles. Definition Rules.

\footnotetext{
* Mestre em Linguística Aplicada pela Universidade Estadual do Ceará (UECE), doutorando do curso de Pós-graduação em Letras da Universidade do Estado do Rio Grande do Norte (UERN), professor do Instituto Federal da Paraíba (IFPB), Campus Catolé do Rocha. E-mail: danielmartynianodesa@ gmail.com 


\section{Introdução}

Um dicionário, um glossário ou qualquer outra obra de natureza semelhante, de língua materna, é acessado principalmente para se esclarecer um significado de alguma palavra. A parte mais lida nessas obras, portanto, é a definição. A necessidade de buscar definição de conceitos passa ser mais constante quando se é iniciante de uma área do conhecimento que se propõe a aprender. Levando isso em consideração, a definição de termos $^{1}$ de uma determinada área deve ser suficiente para tornar compreensível o conceito que se deseja conhecer.

O autor de uma obra que define palavras ou termos precisa ter a disposição uma série de elementos que possam lhe servir de base para escrever definições que atendam a demanda de conhecimento por parte do leitor. Assim, quem produz esse tipo de material necessita conhecer os princípios e as regras que norteiam a elaboração de uma definição. Esses princípios e regras também são úteis para quem se dispõe a analisar definições nos diversos âmbitos, como da pesquisa nas ciências do léxico e áreas afins, além da avaliação de dicionários ou obras similares para uso escolar profissional, entre outras finalidades.

Dessa forma, este trabalho tem como objetivo demonstrar os princípios e regras de definição de termos, ou definição terminológica, numa abordagem didática, de modo que os iniciantes na área de Terminologia, através deste trabalho, possam ter um conhecimento básico sobre definição e serem incentivados ao aprofundamento no assunto. Embora haja uma considerável bibliografia sobre definição terminológica, há uma necessidade maior de textos mais breves e didáticos que possam alcançar um público que está iniciando os estudos sobre definição, em especial, estudantes de Letras e de outros cursos que trabalham com definição.

Sobre o conteúdo deste trabalho, em um primeiro momento, delimitamos o conceito de definição terminológica, partindo do que é definição, na perspectiva de Barros (2004), e sua condição de texto, conforme Krieger e Finatto (2004). Ainda nesse primeiro momento, apresentamos os tipos de definição propostos por Finatto (1998),

\footnotetext{
${ }^{1}$ Normalmente difere-se palavra de termo, sendo a primeira relacionada ao léxico de língua comum, de um idioma, e o segundo relacionado à linguagem de especialidade, ou seja, de linguagem de áreas específicas de conhecimento (ex. linguagem da medicina, linguagem jurídica etc.).
} 
com destaque para as características da definição terminológica, delimitadas por Finatto (2002) e Barros (2004), bem como a diferença entre definição por extensão e definição por compreensão em Barros (2004). No segundo momento, expomos oito princípios com as regras de definição, demonstrados com exemplos de definição satisfatória e insatisfatória, conforme o caso, com base em Vézina et al. (2009).

\title{
1. Delimitando a definição terminológica
}

Barros (2004) sintetiza o conceito de definição, ou enunciado definicional, declarando que é:

\begin{abstract}
O enunciado que descreve o conteúdo semântico-conceptual de uma unidade lexical ou terminológica em posição de entrada de um verbete [...] Consiste em uma paráfrase sinonímica que exprime o conceito designado pela unidade lexical ou terminológica por meio de outras unidades linguísticas [sic]; é um conjunto de informações que são dadas sobre a entrada. (pp. 158-9).
\end{abstract}

Além das propriedades linguísticas expostas por Barros, outros aspectos como autoria, interlocução, condições de produção dos sentidos, entre outros, fazem com que a definição seja um texto, um todo de sentido (KRIEGER e FINATTO, 2004, p. 98).

A definição pode ser encontrada, entre outros contextos, em três tipos básicos de obras: o dicionário de língua, a enciclopédia e o dicionário terminológico. Dependendo de qual desses tipos se encontra, a definição é classificada em três tipos, conforme Finatto:

a) definições lexicográficas caracterizam-se pela predominância de informações linguísticas [sic], tratando mais de "palavras";

b) definições enciclopédicas se ocupam mais de referentes e de descrição de "coisas";

c) definições terminológicas trazem predominantemente conhecimentos formais sobre "coisas" ou fenômenos. (FINATTO, 1998, p. 2). 
Quanto a esta classificação, Barros orienta que essa distinção é prática e didática para aqueles que estão dando seus primeiros passos sobre a definição. A autora esclarece:

\begin{abstract}
O tipo de informação veiculada pela definição e o modelo de estruturação léxico-semântica e semântico-sintáxica do enunciado definicional dependem fundamentalmente da natureza das unidades linguísticas [sic] descritas, das características tipológicas e da finalidade do repertório. Não existe uma definição válida para dois dicionários, uma vez que a cada tipo de obra correspondem algumas características específicas que determinam o conteúdo e a organização do enunciado definicional. É ainda de conhecimento dos lexicógrafos e terminológos que, sendo a definição um elemento-chave na elaboração dos dicionários (de qualquer tipo), é um tema de grande complexidade, sobre o qual reina grande controvérsia e muita discussão sobre sua formulação. (BARROS, 2004, p. 159).
\end{abstract}

Dos três tipos de definição, conforme o escopo deste trabalho, a definição terminológica é destacada aqui. Finatto demonstra o caráter específico dessa definição:

\footnotetext{
Entre diferentes tipos de definição, a definição terminológica (doravante DT) se particulariza por ser o enunciado-texto que dá conta de significados de termos ou de expressões de uma técnica, tecnologia ou ciência. Nesse caso, grosso modo, definir equivale a expressar um determinado saber, uma porção de conhecimento especializado. Esse enunciado envolve, portanto, uma representação conceitual particular, vinculada a um saber técnico, científico ou tecnológico. (FINATTO, 2002, p. 74).
}

A definição terminológica apresenta as seguintes características: 1) adequação ao domínio; 2) estrutura formal e organização conceptual do enunciado definicional; e 3) gênero próximo + diferenças específicas (BARROS, 2004).

De acordo com a primeira característica, a definição de um termo está diretamente ligada à área do conhecimento, ao domínio em que esse termo está inserido. Um mesmo termo, dependendo do domínio a que pertence, pode ter definições diferentes ${ }^{2}$.

\footnotetext{
${ }^{2}$ Ver o exemplo de teclado na subseção 2.8 . 
A segunda característica da definição terminológica está relacionada com a forma e o sentido da definição. A definição terminológica geralmente é iniciada por um hiperônimo, um termo subordinante, que tem uma relação hierárquica superior com um termo subordinado (LOPES e RIO-TORTO, 2007, p. 29). Por exemplo, mamífero é hiperônimo de gato $^{3}$. Nesse caso, uma definição satisfatória de gato iniciar-se-ia com mamífero [...]. Depois do hiperônimo, a definição descreve os traços característicos específicos do conceito definido, de modo a particularizar este conceito e também diferenciá-lo de outros conceitos semelhantes.

Com estreita relação com a segunda característica, a fórmula gênero próximo + diferenças específicas é considerada padrão para a definição terminológica. O conceito de gênero remonta a Aristóteles, que o classificou em gênero próximo, gênero distante e gênero supremo. Com relação à definição e aos conceitos definidos, o gênero próximo corresponde ao hiperônimo imediatamente acima do definido em um determinado sistema conceitual; o gênero distante, ao hiperônimo ainda mais acima do definido, sendo superior ao gênero próximo; o gênero supremo, por sua vez, corresponde ao hiperônimo cujo conceito é genérico, muito amplo, que, a princípio, não está incluído em nenhuma categoria. No sistema conceitual representado pelo esquema exemplificado abaixo (ver quadro 01), tomando como base a palavra cadeira, o gênero próximo é assento, os gêneros distantes são móvel e objeto, e o gênero supremo é coisa. As diferenças específicas são os traços característicos específicos que se sucedem ao hiperônimo, como foi explicado antes. A definição composta por gênero próximo + diferenças específicas é denominada de definição genérica.

\footnotetext{
${ }^{3}$ Por sua vez, gato é hipônimo de mamífero. 


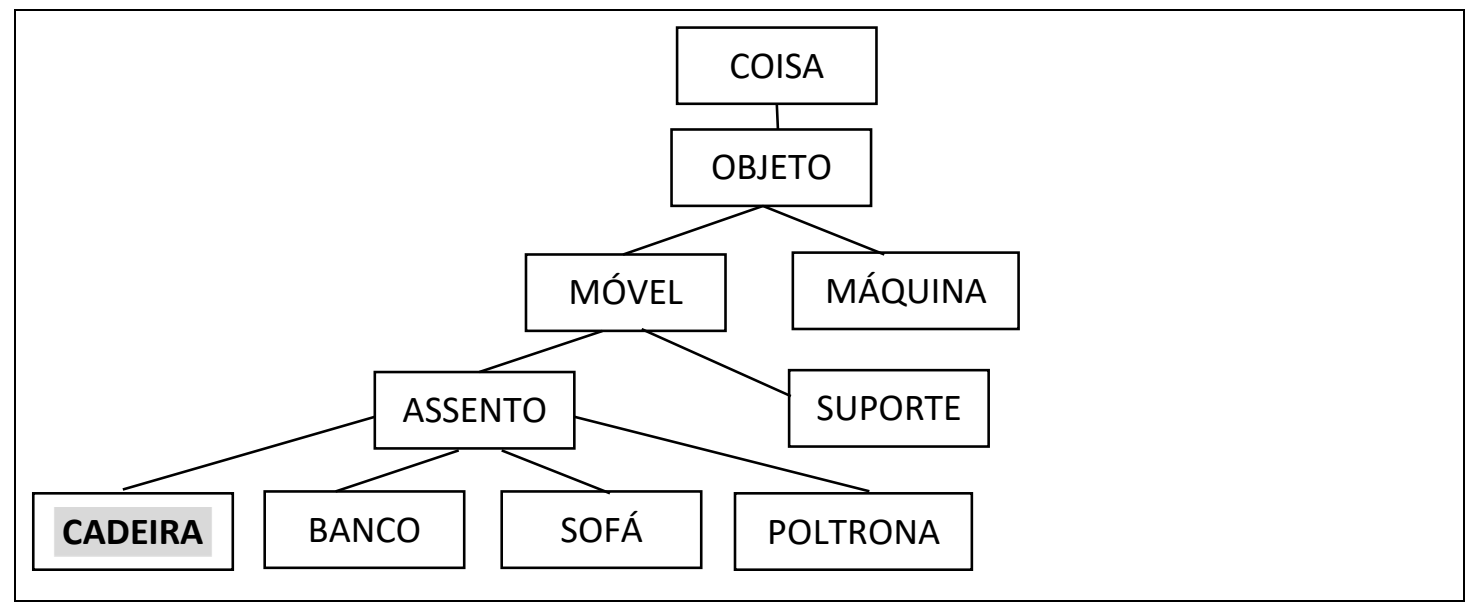

Fonte: Elaboração do autor, 2020.

Barros (2004) distingue definição por extensão e definição por compreensão. A primeira enumera "todas as espécies que estão no mesmo nível de abstração ou todos os objetos individuais que pertencem ao conceito definido" (FELBER, 1984, apud BARROS, 2004, p. 171). A autora exemplifica com a definição do termo corpo humano e aponta que essa definição limita-se a expor as partes que constituem o corpo humano, não havendo descrição das características do termo e dos seus atributos semânticoconceptuais:

Quadro 02 - Definição por extensão de corpo humano

corpo humano: $s$ m $O$ corpo humano é constituído das seguintes partes: cabeça, tronco e membros.

Fonte: Barros, 2004, p. 171.

A definição por compreensão, por sua vez, inclui os atributos semânticoconceptuais, descrevendo o termo por meio de traços característicos distintivos, ou seja, características próprias do conceito definido, que o difere de outros conceitos próximos. Considerada como ideal para a elaboração de obras terminográficas, a definição por compreensão segue o modelo clássico gênero próximo + diferenças específicas, de modo que a definição seja delimitada para uma determinada unidade terminológica ${ }^{4}$ e não outra.

\footnotetext{
${ }^{4}$ Unidade terminológica refere-se a um termo simples, de uma palavra (ex. cadeira) ou a um termo composto, de duas ou mais palavras (ex. corpo humano). 


\section{Princípios e regras de definição}

Os princípios e as regras de definição são discutidas aqui com base em Vézina et al. (2009). Embora o trabalho dos autores seja voltado para a língua francesa, os princípios e regras são aplicáveis para a língua portuguesa.

São oito os princípios de definição, que dão origem a diversas regras. Os autores explicam 31 regras, algumas oriundas de um determinado princípio, outras, de mais de um princípio. Cabe dizer que as regras não são imposições, e sim orientações quanto à produção de definições.

Em virtude da limitação de espaço próprio de um artigo, selecionamos 15 regras que contemplam esses oito princípios para a discussão. Em vez de tratar dos princípios e, na sequência, das regras de modo separado, como fazem os autores, optamos por dedicar cada seção a um princípio e a(s) regra(s) pertinente(s) a esse princípio. Quando uma regra se aplica a mais de um princípio, esta é tratada uma única vez em um princípio e apenas mencionada em outro(s) princípio(s) subsequente(s).

As definições exemplificadas, no domínio da música ${ }^{5}$, foram elaboradas por nós, exceto uma. Nos exemplos em que são demonstradas definições insatisfatórias, os trechos sublinhados representam as partes que motivam tais insuficiências.

\subsection{Princípio da concisão}

Para atender ao princípio da concisão, a definição deve ter as seguintes características: ser breve, expressar apenas o essencial, desconsiderar redundância e palavras desnecessárias e utilizar um conjunto de palavras que permitem resumir ao máximo o conteúdo da definição. O redator da definição deve, portanto, limitar-se aos traços característicos essenciais e necessários, para que a definição não se torne uma definição enciclopédica. Caso haja alguma informação não essencial, mas que se julgue importante, pode ter sua inclusão em uma nota a parte da definição.

Uma das regras que estão adequadas ao princípio da concisão é esta: cada traço característico deve ser mencionado uma única vez. Sendo uma característica do

\footnotetext{
${ }^{5}$ Este trabalho tem relação com a pesquisa sobre terminologia musical, sendo desenvolvida pelo autor deste artigo durante o curso de Doutorado no Programa de Pós-graduação em Letras da Universidade do Estado do Rio Grande do Norte - UERN.
} 
princípio da concisão a expressão do que é unicamente essencial, o uso de locuções como isto é, a saber, neste caso, ou seja, entre outros, deve ser evitado, já que introduzem uma equivalência de significado ou uma explicação, duplicando, assim, um traço característico. Caso haja necessidade de um esclarecimento adicional, recomendase que se faça em uma nota separada da definição. Veja-se um exemplo de definição que não atende a regra explicitada anteriormente:

musicar: compor música, ou seja, uma combinação harmoniosa e expressiva de sons.

Outra regra oriunda do princípio da concisão dá conta de que, em uma definição genérica, o definido deve, em princípio, ser ligado ao gênero próximo. Considerando que um conceito, cujo termo é expresso por $A 1$, faça parte do conceito imediatamente superior, cujo termo é expresso por $A$, e considerando também que a definição do termo $A$ seja conhecida ou esteja presente na mesma obra terminográfica em que está presente a definição do termo $A 1$, o gênero próximo como definidor inicial, expresso pelo termo $A$, deve ser utilizado na definição de A1, a fim de evitar a formulação desnecessária de traços característicos que já estão contemplados na definição do termo A. Para exemplificar, considera-se o termo acorde como $A$ e o termo acorde maior como Al. Na definição do termo acorde maior (A1), o definidor inicial deve ser expresso pelo termo acorde (A) que, por sua vez, é o gênero próximo de acorde maior (Al), já que o conceito de acorde é imediatamente superior ao de acorde maior, como se observa nos exemplos seguintes:

(2) acorde: grupo de dois ou mais sons musicais simultâneos.

(3) acorde maior: acorde formado de uma nota fundamental com uma outra nota formando com a primeira um intervalo de terça maior e, frequentemente, com uma terceira nota formando com a primeira um intervalo de quinta justa.

A regra exposta acima pode ser combinada com esta outra: uma definição não deve incluir traços característicos que já estão implicitamente indicados no hiperônimo. Se, por exemplo, a definição de acorde maior for acorde de dois ou mais 
sons simultâneos formado de uma nota fundamental com uma outra nota [...], então esta regra não foi observada, pois o trecho da definição "de dois ou mais sons simultâneos" aponta um traço característico do conceito representado pelo termo acorde, o que torna a definição maior que o necessário, desconsiderando, assim, o princípio da concisão.

Uma quarta regra que contempla o princípio da concisão orienta que a definição não deve incluir indicação de domínio. Em outras palavras, a definição não poderia, por exemplo, iniciar assim: "termo da área de música que se refere..." No que diz respeito à marcação de domínio (ou subdomínio) colocada à parte da definição, em uma obra terminológica, a indicação de domínio é redundante. No caso de uma obra terminográfica de música, por exemplo, não há necessidade de indicar que o termo é de música. A indicação de subdomínio, por sua vez, demonstra-se adequada quando a obra terminográfica é de um domínio que têm seus subdomínios. Ainda sobre esse tipo de obra na área de música, os termos podem ser indicados por subdomínios como teoria musical, musicologia, harmonia, etc.

\subsection{Princípio da clareza}

A definição é considerada clara quando não é ambígua, no âmbito da forma e do conteúdo. O redator deve selecionar cuidadosamente as palavras da definição de modo a evitar má interpretação ou confusão para o leitor. O princípio da clareza, portanto, é muito importante, tendo em vista que quem procura um significado de um termo em uma obra terminográfica espera que a definição seja de fácil compreensão.

Uma regra que direciona para uma definição clara é que a definição deve incluir todos os traços característicos essenciais para sua compreensão. Para o cumprimento desta regra, não deve haver formulações abertas terminadas em etc., implicando a exclusão de traços característicos essenciais, como ocorre no exemplo seguinte:

solfejar: ler ou entoar as notas dó, ré, mi etc. de uma notação musical.

\subsection{Princípio da adaptação ao público alvo}


Muitos dos princípios de definição aqui expostos estão ligados ao princípio da adaptação ao público alvo. O nível de clareza e concisão das definições, por exemplo, é determinado visando os leitores a quem a obra terminográfica onde estão essas definições é dirigida. Embora os demais princípios sejam muito importantes para a elaboração da definição, consideramos o princípio da adaptação ao público alvo fundamental, pois é a partir da definição do público alvo que o terminógrafo decide como vai ser um dicionário, um glossário ou outra obra do gênero. Assim, há diferenças entre as formas de definição terminológica voltadas para diferentes grupos, como infanto-juvenil, universitários, especialistas, leigos etc.

A regra seguinte, que atende tanto o princípio da adaptação ao público alvo quanto ao princípio da clareza, orienta que a definição deve incluir apenas termos que sejam considerados conhecidos pelo público alvo ou que sejam eles próprios definidos no mesmo repertório terminológico. Essas duas condições são fundamentais para a clareza da definição. Se, por exemplo, esta última condição não for cumprida, a obra terminográfica deixa de cumprir seu papel de esclarecer ao leitor o significado que ele procura, caso, na definição de um termo, encontre outro termo que desconhece e que não tem uma definição para este outro termo. A definição dos termos acorde maior e acorde, exemplificados anteriormente, demonstram como esta regra pode ser cumprida. Em uma mesma obra terminográfica de música, caso não haja a definição de acorde, ou se o leitor não souber o significado deste termo, a definição proposta para acorde maior no exemplo desconsideraria o princípio da clareza e o princípio da adaptação ao público alvo.

\subsection{Princípio da explicitação e da adequação}

A definição que segue o princípio da explicitação e da adequação indica as características essenciais de um conceito de modo preciso e é aplicada restritamente ao conceito definido. O redator deve elaborar a definição de modo completo, evitando excesso de restrição ou de ampliação. Para verificar se a definição é suficientemente explícita e adequada, pode-se fazer um teste com as seguintes perguntas: Todos os $\mathrm{X}$ (os objetos representados pelo termo) são Y (os objetos designados pelo hiperônimo) que possuem essas características (Z)? Todos os Y que possuem características Z são X? Se 
a resposta para as duas perguntas for positiva, a definição atende ao princípio da explicitação e da adequação; caso haja alguma resposta negativa, a definição não atende a esse princípio. Observe-se o próximo exemplo:

$$
\text { violão }[\mathrm{X}] \text { : instrumento }[\mathrm{Y}] \text { do grupo das cordas }[\mathrm{Z}] \text {. }
$$

Aplicando-se o teste de verificação: todos os X (violões) são Y (instrumentos) que têm características $\mathrm{Z}$ (do grupo das cordas)? Sim. Todos os Y (instrumentos) que possuem características $\mathrm{Z}$ (do grupo das cordas) são $\mathrm{X}$ (violões)? Não (há também o violino, a guitarra, a harpa etc. $)^{6}$. Agora o exemplo seguinte:

(6) piano $[\mathrm{X}]$ : instrumento de teclado $[\mathrm{Y}]$ formado por uma grande mesa de som horizontal apoiada por pés, cujas cordas são percutidas por martelos [Z] ${ }^{7}$.

Aplicando-se o teste de verificação: Todos os X (pianos) são Y (instrumentos de teclado) que têm características $\mathrm{Z}$ (formados por uma grande mesa de som horizontal apoiada por pés, cujas cordas são percutidas por martelos)? Não (além dos pianos de cauda, que tem a característica $\mathrm{Z}$, há também os pianos verticais). Todos os $\mathrm{Y}$ (instrumentos de teclado) que possuem características $\mathrm{Z}$ (formados por uma grande mesa de som horizontal apoiada por pés, cujas cordas são percutidas por martelos) são $\mathrm{X}$ (pianos)? Sim.

Quando apenas a primeira pergunta do teste recebe resposta positiva, a definição é muito ampla, insuficiente, pois abrange não apenas o conceito definido, mas também outros conceitos, como ocorre com a definição do termo violão. Já quando apenas a segunda pergunta recebe resposta positiva, a definição é muito restrita, excluindo uma parte da extensão do conceito definido, como acontece com a definição de piano. As

\footnotetext{
${ }^{6}$ Exemplo adaptado do Cours de terminologie Pas à Pas, no site da Unité de formation et de recherche d'Études interculturelles de langues appliquées (UFR EILA) da Universidade Paris-Diderot - Paris VII (http://hosting.eila.univ-paris-diderot.fr/ juilliar/termino/index.htm) (apud Vézina et al. 2009, p. 13)

${ }^{7}$ A definição de piano no exemplo foi extraído de Vézina et al. (2009, p. 14).
} 
definições exemplificadas, portanto, não atendem ao princípio da explicitação e da adequação.

Com relação às regras, uma das maneiras de atender o princípio da explicitação e da adequação é fazer com que a definição tenha uma forma afirmativa. Conforme esta regra, a definição deve dizer o que o conceito é (7), em vez de dizer o que o conceito não é (8):

(7) linha suplementar: linha horizontal curta localizada acima ou abaixo da pauta onde são escritas as notas que excedem o limite superior ou inferior da extensão de notas na pauta.

(8) linha suplementar: linha que nãa faz parte da pauta.

Outra maneira de atender o princípio da explicitação e da adequação é considerar que os traços característicos intrínsecos devem preceder os traços característicos extrínsecos, quando a definição apresenta esses dois traços característicos. Os traços característicos intrínsecos referem-se à constituição, forma, dimensões e cor do objeto a ser definido, enquanto que os traços característicos extrínsecos dizem respeito a destino, local, função, proveniência e utilidade do objeto. No exemplo (9), a definição de arco apresenta primeiro o traço característico intrínseco de composição (consiste em uma vara fina, arqueada, flexível, provido de crina de uma extremidade à outra), seguido do traço característico extrínseco de utilidade (usado para por em vibração as cordas de instrumentos de cordas friccionadas, produzindo um som musical).

(9) arco: objeto que consiste em uma vara fina, arqueada, flexível, provido de crina de uma extremidade à outra, usado para por em vibração as cordas de instrumentos de cordas friccionadas, produzindo um som musical.

Além dessas duas regras, o princípio da explicação e da adequação também é observado quando a definição inclui todos os traços característicos essenciais para a sua compreensão. Esta regra foi tratada na subseção 2.2. 


\subsection{Princípio da substituição}

Para que esteja conforme o princípio da substituição, a definição deve ser redigida de modo que, teoricamente, possa substituir o termo definido, e vice-versa, em um enunciado e em um determinado contexto, sem que haja perda ou modificação de significado, e também sem que haja quebra sintática.

Com o intuito de seguir esse princípio, é fundamental que o definidor inicial deva ser da mesma categoria gramatical que o termo definido. Esta regra deve ser observada principalmente se a categoria gramatical for um substantivo ou um verbo, ou seja, se o termo definido for um substantivo, o definidor inicial também deve ser um substantivo (10); se o termo definido for um verbo, o definidor inicial também deve ser um verbo (11):

(10) pauta [subst.]: conjunto de cinco linhas horizontais, paralelas e equidistantes, formando quatro espaços entre elas, onde se escrevem os sinais musicais.

(11) instrumentar [v.]: escrever as partes de uma obra musical destinadas a cada instrumento para serem executadas em conjunto.

$\mathrm{Na}$ frase "vamos iniciar a execução da peça a partir da segunda pauta", a substituição do termo pauta pela sua definição, resultando em "vamos iniciar a execução da peça a partir do segundo conjunto de cinco linhas horizontais, paralelas e equidistantes, formando quatro espaços entre elas, onde se escrevem os sinais musicais." (observando-se a mudança do sintagma da segunda por do segundo, para concordar em gênero com conjunto), não provocou perda ou modificação de significado, e nem provocou uma quebra sintática. Desse modo, a definição de pauta segue o princípio da substituição.

Outra regra que garante a adequação ao princípio da substituição é que não deve haver discrepância de número entre o definidor inicial e o termo definido. Em outros termos, se o termo definido estiver no singular, o definidor inicial também deve estar no singular; se o termo definido estiver no plural, o definidor inicial também deve estar no plural. Duas exceções a esta regra: a) quando um termo que está no plural se 
refere a um conceito no singular; b) quando a definição do termo que está no plural é baseada em uma relação todo/parte (Conjunto de..., Família de..., Grupo de..., etc.):

(12) metais: conjunto de instrumentos de sopro feitos de metais, em sua maioria, cujo som é produzido pela vibração dos lábios do executante sobre um bocal.

As regras da não inclusão de indicação de domínio na definição e da inclusão de todos os traços característicos essenciais para a compreensão da definição, desenvolvidas respectivamente nas subseções 2.1 e 2.2 também se aplicam no princípio da substituição.

\subsection{Princípio da não-tautologia}

A definição tautológica consiste em expressar um conceito utilizando termos idênticos, sinônimos ou equivalentes ao termo definido que não acrescentam informação necessária para a compreensão do termo definido. Essa definição é considerada defeituosa, pois compromete o propósito da definição, deixando de observar, além do princípio da não-tautologia, outros princípios, como o da clareza por exemplo.

Uma regra a ser observada para a elaboração de uma definição não-tautológica é: Uma definição não deve ser introduzida pelo termo a ser definido, nem incluir esse termo (ou um de seus sinônimos) ou um termo da mesma família. O próximo exemplo mostra uma definição que vai contra essa regra:

(13) tímpano: tímpano geralmente usado em orquestras sinfônicas que tem características de um tímpano.

Um leitor que encontra a definição de tímpano exemplificado acima, em que aparece duas vezes o termo definido (na definição), não terá elucidada a sua dúvida sobre o significado de tímpano. A definição tautológica, portanto, é malsucedida no seu objetivo de levar um leitor a compreender o significado de um termo. 


\subsection{Princípio da generalização e da abstração}

Afirmar que a definição deve ser geral e abstrata significa dizer que um conceito deve ser definido sem foco em um objeto em particular. $\mathrm{O}$ redator deve tomar o cuidado de definir um conceito sem deixar nenhum traço característico que se aplica a uma representação que lhe seja familiar. Assim, a definição deve ser isenta do que se segue: a) de traços característicos supérfluos ou acidentais, ou seja, ausentes na maioria dos casos; b) de traços característicos que podem estar brevemente em desuso, c) de excesso de exemplos; d) de particularização do conceito do ponto de vista espacial (por exemplo, do local onde o redator está localizado), temporal (pelo uso de formulações como hoje em dia, atualmente, etc.), pessoal (por exemplo, citação de um autor), ou contextual.

No que diz respeito ao regulamento, para que a definição atenda ao princípio da generalização e da abstração, ela deve adotar um ponto de vista neutro, sendo, portanto, isenta de comentários subjetivos. O exemplo a seguir demonstra a inserção de um juízo de valor na definição, ocasionando um desvio a essa regra:

trítono: intervalo de quarta aumentada de sonoridade desagradável.

Também, para se adequar a esse princípio, a definição não deve incluir traços característicos que possam rapidamente se tornar obsoletos ou que correspondam a características "estereotipadas" que não se aplicam a todos os objetos que constituem a classe designada pelo termo definido. $O$ exemplo de definição seguinte dá a entender que o violino é utilizado exclusivamente para executar peças de música erudita, quando esse instrumento musical também pode ser utilizado para executar obras musicais de diversos estilos em diversos contextos:

(15) violino: instrumento de cordas friccionadas mais agudo, com quatro cordas, utilizado para executar peças de música erudita. 
O princípio da generalização e da abstração também compartilha a regra de que a definição deve incluir todos os traços característicos essenciais para sua compreensão (ver subseção 2.2).

\subsection{Princípio da previsibilidade}

No princípio da previsibilidade, a definição deve ser redigida de modo que se preveja o lugar que o conceito ocupará, ou que se reflita sobre o lugar que o conceito ocupa, em um sistema conceitual. Para isso, o redator deve considerar o conceito do termo definido como parte de um sistema conceitual, tanto na escolha de um hiperônimo que identifique o sistema a que o conceito pertence quanto na delimitação dos traços característicos que possam diferenciar o conceito definido de outros conceitos de um mesmo sistema conceitual.

Assim, para contemplar o princípio da previsibilidade, uma das regras é: na descrição de um conceito, deve-se levar em consideração o domínio (e, se aplicável, o subdomínio). A escolha do definidor inicial geralmente é influenciada pela área da qual o conceito a ser definido faz parte. Por exemplo, o termo teclado, na área da informática, é definido como um dispositivo de entrada; na área de telecomunicações, é definido como parte de um aparelho telefônico ${ }^{8}$. Já na área de música, teclado é definido como um instrumento musical eletrônico ${ }^{9}$ :

Outra regra que contempla o princípio da previsibilidade dá conta de que o uso de um traço característico do conceito como definidor inicial deve ser evitado. A observância dessa regra garante que a definição situe o conceito em um sistema conceitual, o que é fundamental em uma definição terminológica. O exemplo abaixo mostra como é uma definição que não cumpre essa regra (compare com a definição no exemplo (9)):

\footnotetext{
${ }^{8}$ A demonstração das definições de teclado na área de informática e de telecomunicações foi extraída de Vézina et al. (2009, p. 20).

${ }^{9}$ Ainda na área de música, o termo teclado pode ser definido como conjunto de teclas de um instrumento musical.
} 
arco: vara fina, arqueada, flexível que compõe o objeto contendo crina de uma extremidade à outra, usada para por em vibração as cordas de instrumentos de cordas friccionadas, produzindo um som musical.

\section{Considerações finais}

A exposição feita neste trabalho contemplou a natureza da definição terminológica de uma maneira introdutória e, principalmente, os princípios e as regras de definição terminológica. A temática aqui desenvolvida é de muita relevância para redatores de definição, pesquisadores e para iniciantes na área.

Inicialmente a definição terminológica foi delimitada, tendo como ponto de partida a 'definição da definiç̧ão' de Barros (2004) e a sua condição textual, seguida dos tipos de definição propostos por Finatto (1998), dentre as quais está a definição terminológica. Esta definição, com caráter específico de lidar com significados de termos ou de expressões relacionadas a uma técnica, tecnologia ou ciência, adequa-se a um domínio, apresenta estrutura formal e organização conceptual e é estruturada predominantemente pela fórmula gênero próximo + diferenças específicas. A definição terminológia pode ser por extensão, quando enumera as espécies ou objetos individuais de um conceito, e por compreensão, considerada ideal para a elaboração de obras terminográficas, quando descreve o termo por meio de traços característicos distintivos.

Na sequência, foram desenvolvidos os oito princípios de definição, com suas regras, fundamentados em Vézina et al. (2009). No princípio da concisão, a definição deve ter o mínimo de palavras possível. Para atender o princípio da clareza, a definição não deve ser ambígua. A definição deve ser redigida tendo em vista o princípio da adaptação ao público-alvo. No princípio da explicitção e da adequação, a definição não deve ser ampla demais, nem restrita demais. A definição e o termo definido devem ser equivalentes para atender ao princípio da substituição.

O princípio da não-tautologia, por sua vez, prevê que o enunciado definitório não deve conter termos idênticos, sinônimos ou equivalentes ao termo definido para que não haja prejuízo na compreensão do significado do termo definido. O redator da definição, para estar de acordo com o princípio da generalização e da abstração, não 
deve deixar nenhum traço característico que se aplica a uma representação particular. Por fim, a definição deve ser redigida de modo que se preveja (ou que se reflita sobre) o lugar que o conceito ocupa em um sistema conceitual.

A exposição sobre a definição terminológica, seus princípios e regras, portanto, é muito importante, especialmente para estudantes de cursos (ou de disciplinas) em que é necessário lidar com esse tipo de definição, particularmente para os estudantes de Letras.

\section{REFERÊNCIAS}

BARROS, L. A. Curso Básico de Terminologia. São Paulo: Editora da Universidade de São Paulo, 2004.

FINATTO, M. J. B. Elementos lexicográficos e enciclopédicos na definição terminológica: questões de partida. Organon, Porto Alegre, vol. 12/n.26, p. 1-8, 1998. Disponível em: https://seer.ufrgs.br/index.php/organon/article/view/29563 . Acesso em: 24 mar. 2020.

FINATTO, M. J. B. O papel da definição de termos técnico-científicos. Revista da ABRALIN, vol.1/n. 1, p. 73-97, jul. 2002.

KRIEGER, M. da G.; FINATTO, M. J. B. Introdução à Terminologia: teoria e prática. São Paulo: Contexto, 2004.

LOPES, A. C. M.; RIO-TORTO, G. Semântica. Alfragide: Caminho, 2007

VÉZINA, R. et al. La rédaction de définitions terminologiques. Version abrégée et adaptée par Jean Bédard et Xavier Darras. Montréal: Office québécois de la langue française, 2009. 